\title{
Natural radioactivity in Italian ceramic tiles
}

\author{
S. Righi ${ }^{1,2}$, R. Guerra ${ }^{1,2}$, M. Jeyapandian ${ }^{1,3}$, S. Verità ${ }^{1,2}$ and A. Albertazzi ${ }^{4}$ \\ ${ }^{1}$ Interdepartmental Centre for Environmental Science Research, Bologna University, \\ via S.Alberto 163, 48100 Ravenna, Italy \\ 2 Department of Physics, Bologna University, Viale Pichat 6/2, 40127 Bologna, Italy \\ 3 Solid State and Radiation Physics Lab., Department of Physics, Bharathiar University, \\ 641046 Coimbatore, India \\ ${ }^{4}$ Italian Ceramic Centre, via Martelli 26, 40138 Bologna, Italy
}

\begin{abstract}
Zircon is the mostly widely occurring zirconium-containing mineral mined commercially. Thorium and uranium may substitute for zirconium in the zircon crystal lattice. The radioactivity levels in zircon lies typically within the ranges $500-1000 \mathrm{~Bq} \mathrm{~kg}^{-1}$ for ${ }^{232} \mathrm{Th}$ and $1000-5000 \mathrm{~Bq} \mathrm{~kg}^{-1}$ for ${ }^{238} \mathrm{U}$ [1]. One of the most important use of zircon is as opacifier for ceramic tiles. Body of ceramic tiles is a mixture of different raw materials, including: clays, quartz materials and feldspathic materials. The body may be glazed or left unglazed. Due to the presence of zircon in the glaze or in the body, ceramic tiles can show natural activity concentration significantly higher than the average values of Earth's crust. This study contains a summary of results obtained by a survey on Italian ceramic tiles collected over three years (2005-2007). About one hundred ceramic tiles were analysed. The survey consisted of measurement of ${ }^{226} \mathrm{Ra},{ }^{232} \mathrm{Th}$ and ${ }^{40} \mathrm{~K}$ activity concentrations and of the gamma-index [2] and radium-equivalent $[3,4]$ calculation. The activity concentrations of ${ }^{226} \mathrm{Ra},{ }^{232} \mathrm{Th}$ and ${ }^{40} \mathrm{~K}$ result in the order of 100,50 and $500 \mathrm{~Bq} \mathrm{~kg}^{-1}$, respectively. Gamma index and radium equivalent activity have been found well below the acceptable limit in most of the samples.
\end{abstract}

\section{INTRODUCTION}

All building materials contain various amounts of natural radioactive nuclides. Materials derived from rock and soil contain mainly natural radionuclides of the uranium $\left({ }^{238} \mathrm{U}\right)$ and thorium $\left({ }^{232} \mathrm{Th}\right)$ series, and the radioactive isotope of potassium $\left({ }^{40} \mathrm{~K}\right)$. In the uranium series, the decay chain segment starting from radium $\left({ }^{226} \mathrm{Ra}\right)$ is radiologically the most important and, therefore, reference is often made to radium instead of uranium [3]. The knowledge of the natural radioactivity of building materials is important for the determination of population exposure to radiations, as most of the people spend $\sim 80 \%$ of their time indoors [5]. High levels of radioactivity in construction materials can increase external and internal indoor exposure. Currently, a worldwide effort is underway to measure the activity concentrations in building materials.

Ceramic tiles are one of the commonly used decorative building materials: they are made of a mixture of earthly materials that has been pressed into shape and fired at high temperature. The body of ceramic tiles may than be glazed or left unglazed. Dust-pressed ceramic tiles with water absorption levels $<0.5 \%$, and high mechanical and chemical characteristics are known as 'Fully Vitrified Stoneware' or 'Porcelain Stoneware'. Due to the addition of zircon, as opacifier or whitening, ceramic tiles can show natural activity concentration significantly higher than the average values of Earth's crust.

Zircon is used in a wide variety of applications, either as zircon sand directly from the mine, as zircon flour, as opacifier grade zircon or chemically processed or fused to produce synthetic zirconia and zirconium chemicals. There are three main markets for zircon - ceramics, refractories, foundries of which the ceramics industry is the largest by volume (53\% of the total market). Typically, a zircon concentrate will have a $\mathrm{ZrO}_{2}+\mathrm{HfO}_{2}$ content of $65-66 \%$, a TiO 2 content of $0.10 \%$ and an $\mathrm{Fe}_{2} \mathrm{O}_{3}$ content of $0.05-0.12 \%$ [6]. 
This report contains a summary of results obtained on ceramic tiles collected over three years (2005-2007) from several Italian manufacturing firms. Sixteen samples of porous fired tiles and seventy samples of porcelain stoneware tiles were analysed. The survey consisted of measurement of ${ }^{226} \mathrm{Ra}$, ${ }^{232} \mathrm{Th}$ and ${ }^{40} \mathrm{~K}$ activity concentrations by HPGe gamma-spectroscopy and of the gamma-index and radium-equivalent calculation. The results of this investigation are compared with the findings of similar studies carried out in other countries.

\section{MATERIALS AND METHODS}

\subsection{Gamma spectrometry measurements}

Radionuclide activities were assayed by $\gamma$-ray spectrometry, using a hyperpure n-type germanium coaxial detector (22.6\% efficiency, $1.9 \mathrm{keV}$ resolution) coupled to a multichannel analyser. Commercial software Gamma Silena2000 was used for data analysis. Samples were dried, homogenized, packed, and sealed in $450 \mathrm{ml}$ Marinelli beakers. Samples were sealed for at least 21 days prior to analysis to allow for equilibrium between ${ }^{226} \mathrm{Ra}$ and ${ }^{222} \mathrm{Rn}$. Count times were typically in the range 10,000 to $60,000 \mathrm{~s}$, giving a measurement precision of between ca. $\pm 5 \%$ and $\pm 10 \%$ at the $95 \%$ level of confidence. The background was subtracted from each spectrum.

The detector was calibrated using a mixed radionuclide solution, containing ${ }^{241} \mathrm{Am},{ }^{109} \mathrm{Cd},{ }^{57} \mathrm{Co}$, ${ }^{139} \mathrm{Ce},{ }^{60} \mathrm{Co},{ }^{113} \mathrm{Sn},{ }^{85} \mathrm{Sr},{ }^{137} \mathrm{Cs}$ and ${ }^{88} \mathrm{Y}$, certified by the Commissariat à l'Energie Atomique (CEA), covering an energy range of approximately $60-1800 \mathrm{keV}$. Quality assurance of the measurements were assessed through the analysis of Standard Reference Material IAEA soil-375. Thorium-232 is not measurable directly because it does not emit any penetrating $\gamma$-rays. That's why the measurement relied on detecting emissions from their progeny. Thorium-232 activities were measured by taking the mean activity of photopeaks of the daughter nuclides ${ }^{228} \mathrm{Ac}(338.40,911.07$ and $968.90 \mathrm{keV})$ and ${ }^{212} \mathrm{~Pb}$ $(238.63 \mathrm{keV})$. Similarly, ${ }^{226} \mathrm{Ra}$ activities were calculated from the activity of its short-lived daughters ${ }^{214} \mathrm{~Pb}$ at 295.2 and $351.9 \mathrm{keV}$, and ${ }^{214} \mathrm{Bi}$ at $609.3 \mathrm{keV}$. Activities of ${ }^{40} \mathrm{~K}$ were determined directly from its $\gamma$-emission at $1460.83 \mathrm{keV}$.

The activity levels for radionuclides in the measured samples are computed using the following equation:

$$
A=\frac{c p s}{\varepsilon \gamma m}
$$

where $A$ is the activity concentration of a certain radionuclide expressed in $\mathrm{Bq} \mathrm{kg}^{-1}$ dry weight, cps is the net counting rate of sample subtracted from background (counts per seconds), $\varepsilon$ is the counting efficiency of the used detector, is the absolute transition probability of $\gamma$-decay and $m$ is the dried sample weight expressed in $\mathrm{kg}$.

\subsection{Radium equivalent activity calculation}

Radium equivalent activity $\left(\mathrm{Ra}_{\mathrm{eq}}\right)$ is a very common index used to represent the specific activity of ${ }^{226} \mathrm{Ra},{ }^{232} \mathrm{Th}$ and ${ }^{40} \mathrm{~K}$ by a single quantity which takes into account the radiation hazards associated with them. $\mathrm{Ra}_{\mathrm{eq}}$ is a weighted sum of activities of the above three radionuclides based on the estimation that $370 \mathrm{~Bq} \mathrm{~kg}^{-1}$ of ${ }^{226} \mathrm{Ra}, 259 \mathrm{~Bq} \mathrm{~kg}^{-1}$ of ${ }^{232} \mathrm{Th}$ or $4810 \mathrm{~Bq} \mathrm{~kg}^{-1}$ of ${ }^{40} \mathrm{~K}_{\text {produce the same gamma ray }}$ dose. It is defined as $[3,4]$ :

$$
R a_{e q}=C_{R a}+1.43 C_{T h}+0.077 C_{K}
$$

where $C_{R a}, C_{T h}$ and $C_{K}$ are the activity concentration of ${ }^{226} \mathrm{Ra},{ }^{232} \mathrm{Th}$ and ${ }^{40} \mathrm{~K}\left(\mathrm{~Bq} \mathrm{~kg}^{-1}\right)$ respectively.

The maximum value of $\mathrm{Ra}_{\mathrm{eq}}$ in building materials must be less than $370 \mathrm{~Bq} \mathrm{~kg}^{-1}$ for safe use, i.e. to keep the external dose below $1.5 \mathrm{mGy}$ per year. 


\subsection{Activity concentration index calculation}

A number of indexes dealing with the assessment of the excess gamma radiation originating from building materials have been proposed [7-11]. In this study, the gamma-index was calculated as proposed by the European Commission [2]. The Commission suggests that building materials should be exempted from all restrictions concerning their radioactivity if the excess gamma radiation originating from them increases the annual effective dose of a member of the public by $0.3 \mathrm{mSv}$ at the most. On the contrary, doses higher than $1 \mathrm{mSv}$ should be accepted only in some very exceptional cases where materials are used locally. The European Commission recommends that controls should be based on a dose in the range $0.3-1 \mathrm{mSv} \mathrm{y}^{-1}$. This is the excess gamma dose to that received outdoors. The European Commission has proposed the following activity concentration index $(I)$ for identifying whether a dose criterion is met:

$$
I=\frac{C_{R a}}{300 \mathrm{~Bq} \mathrm{~kg}^{-1}}+\frac{C_{T h}}{200 \mathrm{~Bq} \mathrm{~kg}^{-1}}+\frac{C_{K}}{3000 \mathrm{~Bq} \mathrm{~kg}^{-1}}
$$

where $C_{R a}, C_{T h}$ and $C_{K}$ are the activity concentration of ${ }^{226} \mathrm{Ra},{ }^{232} \mathrm{Th}$ and ${ }^{40} \mathrm{~K}\left(\mathrm{~Bq} \mathrm{~kg}^{-1}\right)$ respectively, in the building material. The activity concentration index shall not exceed the values shown in Table 1 . Note that the activity concentration index should be used only as a screening tool for identifying materials which might be of concern. Any actual decision on restricting the use of a material should be based on a separate dose assessment. Such assessment should be based on scenarios where the material is used in a typical way for the type of material in question.

Table 1. Maximum recommended values of activity concentration index depending on the dose criterion, and the way and the amount the material is used in a building.

\begin{tabular}{|l|l|l|}
\hline Dose Criterion & $0.3 \mathrm{mSv} \mathrm{y}^{-1}$ & $1 \mathrm{mSv} \mathrm{y}^{-1}$ \\
\hline Materials used in bulk amounts e.g. bricks & $\mathrm{I} \leq 0.5$ & $\mathrm{I} \leq 1$ \\
\hline Superficial and other materials with restricted use: tiles boards, etc & $\mathrm{I} \leq 2$ & $\mathrm{I} \leq 6$ \\
\hline
\end{tabular}

\section{RESULTS AND DISCUSSION}

Radium-226, ${ }^{232} \mathrm{Th}$, and ${ }^{40} \mathrm{~K}$ activity concentrations measured in the tiles are presented in figures 1,2 and 3 , respectively. Tables 2 and 3 report the summary statistics of porous fired and porcelain stoneware tiles, respectively. The activity concentration of ${ }^{226} \mathrm{Ra}$ has been found to be varying from 36 to $87 \mathrm{~Bq} \mathrm{~kg}^{-1}$ (mean value $53 \pm 15 \mathrm{~Bq} \mathrm{~kg}^{-1}$ ) in porous fired tiles, while in porcelain stoneware tiles the activity concentration of ${ }^{226} \mathrm{Ra}$ varies from 20 to $707 \mathrm{~Bq} \mathrm{~kg}^{-1}$ (mean value $114 \pm 118 \mathrm{~Bq} \mathrm{~kg}^{-1}$ ). The activity concentration of ${ }^{232} \mathrm{Th}$ ranges from $38 \mathrm{~Bq} \mathrm{~kg}^{-1}$ to $86 \mathrm{~Bq} \mathrm{~kg}^{-1}$ and $33 \mathrm{~Bq} \mathrm{~kg}^{-1}$ to $145 \mathrm{~Bq} \mathrm{~kg}^{-1}$ with the mean value of $53 \pm 12 \mathrm{~Bq} \mathrm{~kg}^{-1}$ and $55 \pm 23 \mathrm{~Bq} \mathrm{~kg}^{-1}$ in porous fired and porcelain stoneware tiles, respectively. Finally, the activity concentration of ${ }^{40} \mathrm{~K}$ lies between 411 and $996 \mathrm{~Bq} \mathrm{~kg}^{-1}$ and between 158 and $850 \mathrm{~Bq} \mathrm{~kg}^{-1}$ in porous fired and porcelain stoneware tiles, respectively. The comparison of ${ }^{226} \mathrm{Ra},{ }^{232} \mathrm{Th}$, and ${ }^{40} \mathrm{~K}$ activity concentrations in porous fired tiles (table 2 ) and those averagely measured in soils (table 4) shows that they are completely comparable. Instead, natural activity concentrations in porcelain stoneware tiles (table 3) can be significantly higher than those averagely measured in soils, especially for ${ }^{226} \mathrm{Ra}$. The higher natural activity concentrations found in porcelain stoneware tiles can be explained through the larger amount of zircon added with respect to porous fired tiles as reported, for example by Bruzzi et al. [12]. Note that zircon usually contains $500-1000 \mathrm{~Bq} \mathrm{~kg}^{-1}$ of ${ }^{232} \mathrm{Th}$ and $1000-5000 \mathrm{~Bq} \mathrm{~kg}^{-1}$ of ${ }^{238} \mathrm{U}$ [1] and several zircon sands commonly used in Italian ceramic industries have shown the activity concentrations of ${ }^{232} \mathrm{Th}$ and ${ }^{238} \mathrm{U}$ between 360 to $1100 \mathrm{~Bq} \mathrm{~kg}^{-1}$ and 1800 to $3150 \mathrm{~Bq} \mathrm{~kg}^{-1}$, respectively [13]. 


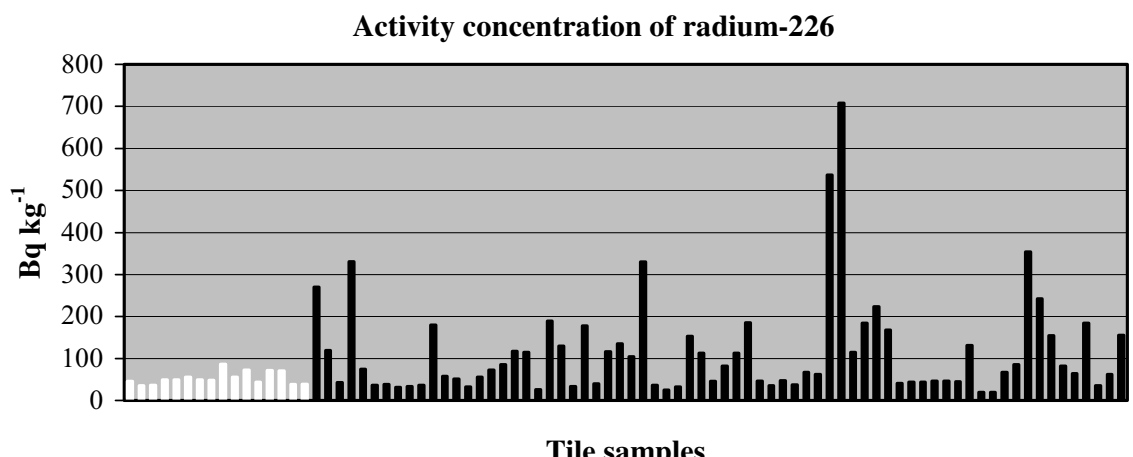

Figure 1. Radium-226 activity concentrations measured in porous fired (white bars) and porcelain stoneware (black bars) tiles.

Activity concentration of thorium-232

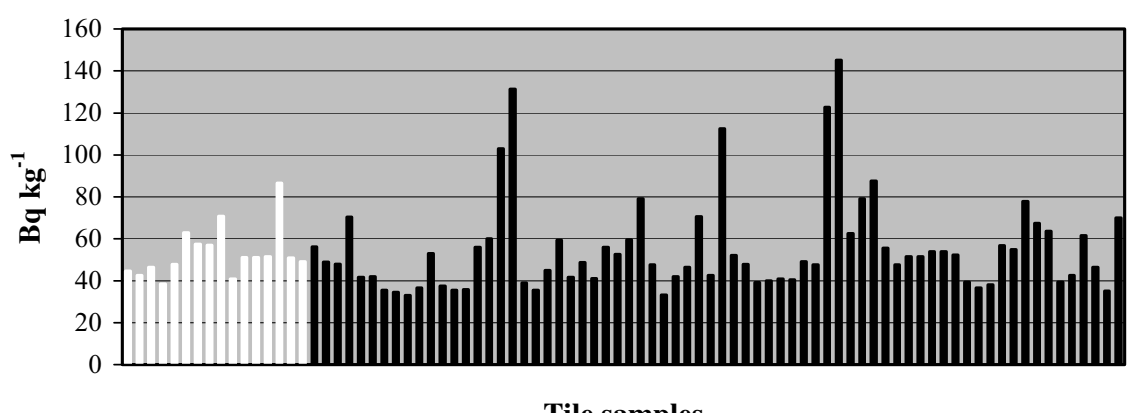

Tile samples

Figure 2. Thorium-232 activity concentrations measured in porous fired (white bars) and porcelain stoneware (black bars) tiles.

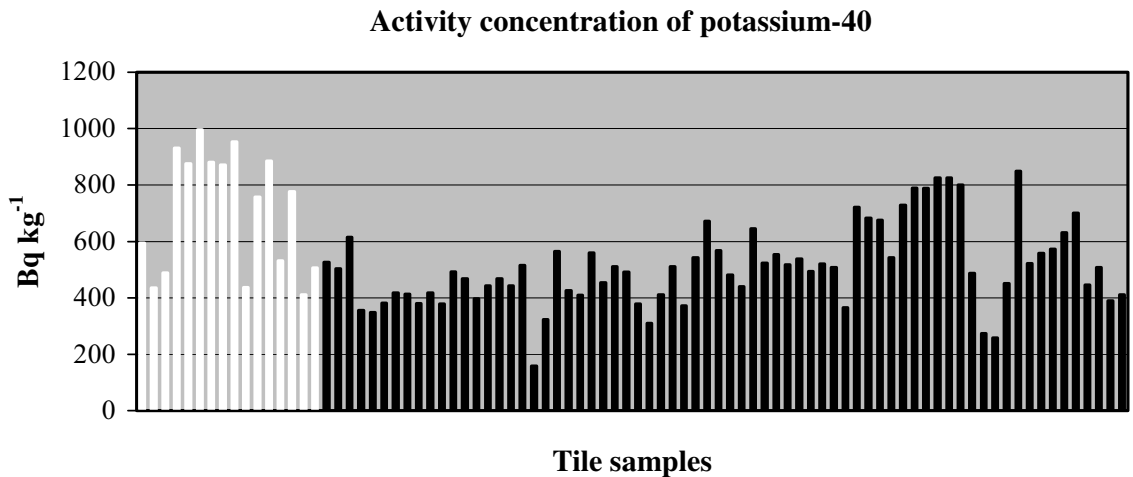

Figure 3. Potassium- 40 activity concentrations measured in porous fired (white bars) and porcelain stoneware (black bars) tiles.

Summary statistics of the radium equivalent $\left(\mathrm{Ra}_{\mathrm{eq}}\right)$ activities for porous fired and porcelain stoneware tiles are given in table 2 and 3 respectively. The value of $\mathrm{Ra}_{\mathrm{eq}}$ of porous fired and porcelain stoneware tiles is ranging from 130 to 261 and 93 to $943 \mathrm{~Bq} \mathrm{~kg}^{-1}$, respectively. The mean value of $\mathrm{Ra}_{\mathrm{eq}}$ for porous fired and porcelain stoneware tiles is $183 \pm 39$ and $232 \pm 143 \mathrm{~Bq} \mathrm{~kg}^{-1}$, respectively. From the results obtained, there's an evidence of considerable variations not only in the $\mathrm{Ra}_{\mathrm{eq}}$ of the 
Table 2. Summary statistics of natural radioactivity content of porous fired tiles.

\begin{tabular}{|l|c|c|c|c|c|}
\hline & $\begin{array}{c}{ }^{\mathbf{2 2 6}} \mathbf{R a} \\
\left(\mathbf{B q ~ k g}^{-1}\right)\end{array}$ & $\begin{array}{c}{ }^{\mathbf{2 3 2}} \mathbf{T h} \\
\left(\mathbf{B q ~ k g}^{-1}\right)\end{array}$ & $\begin{array}{c}{ }^{\mathbf{4 0}} \mathbf{K} \\
\left(\mathbf{B q ~ k g}^{-\mathbf{1}}\right)\end{array}$ & $\begin{array}{c}\mathbf{R a}_{\mathbf{e q}} \\
\left(\mathbf{B q ~ k g}^{-\mathbf{1}}\right)\end{array}$ & $\mathbf{I}$ \\
\hline $\mathrm{N}^{\circ}$ of samples & 16 & 16 & 16 & 16 & 16 \\
\hline Minimum & 36 & 38 & 411 & 130 & 0.48 \\
\hline Maximum & 87 & 86 & 996 & 261 & 0.96 \\
\hline Mean & 53 & 53 & 708 & 183 & 0.68 \\
\hline Standard deviation & 15 & 12 & 214 & 39 & 0.15 \\
\hline Skewness & 0.9 & 1.6 & -0.2 & 0.6 & 0.5 \\
\hline
\end{tabular}

Table 3. Summary statistics of natural radioactivity content of porcelain stoneware tiles.

\begin{tabular}{|l|c|c|c|c|c|}
\hline & $\begin{array}{c}\mathbf{2 2 6}^{\mathbf{R a}} \\
\left(\mathbf{B q ~ k g}^{-\mathbf{1}}\right)\end{array}$ & $\begin{array}{c}{ }^{\mathbf{2 3 2}} \mathbf{T h} \\
\left(\mathbf{B q ~ k g}^{-\mathbf{1})}\right.\end{array}$ & $\begin{array}{c}{ }^{\mathbf{4 0}} \mathbf{K} \\
\left(\mathbf{B q ~ k g}^{-\mathbf{1}}\right)\end{array}$ & $\begin{array}{c}\mathbf{R a}_{\mathbf{e q}} \\
\left(\mathbf{B q ~ k g}^{-\mathbf{1}}\right)\end{array}$ & $\mathbf{I}$ \\
\hline $\mathrm{N}^{\circ}$ of samples & 70 & 70 & 70 & 70 & 70 \\
\hline Minimum & 20 & 33 & 158 & 93 & 0.34 \\
\hline Maximum & 708 & 145 & 850 & 943 & 3.2 \\
\hline Mean & 114 & 55 & 509 & 232 & 0.83 \\
\hline Standard deviation & 118 & 23 & 144 & 143 & 0.48 \\
\hline Skewness & 2.3 & 2.2 & 0.5 & 2.7 & 2.7 \\
\hline
\end{tabular}

two different types of tiles, but also within the same type. Large variation in $\mathrm{Ra}_{\mathrm{eq}}$ activities has been reported in many studies on natural radioactivity in building materials. For example, in 1985 Beretka and Mathew [4] calculated $\mathrm{Ra}_{\mathrm{eq}}$ values ranging between 15 and $883 \mathrm{~Bq} \mathrm{~kg}^{-1}$ in Australian building materials. The values obtained by Amrani and Tahtat [14] in Algerian building materials ranged from 28 to $190 \mathrm{~Bq} \mathrm{~kg}^{-1}$. In Egypt, Ahmed [15] recorded the lowest values in mud and clay bricks (about $100 \mathrm{~Bq} \mathrm{~kg}^{-1}$ ), and the highest ones in granites and marbles (about $400 \mathrm{~Bq} \mathrm{~kg}^{-1}$ ). The recommended maximum levels of radium equivalents for building materials to be used for homes, i.e., to keep the external dose below $1.5 \mathrm{mGy}^{-1}$, is less than $370 \mathrm{~Bq} \mathrm{~kg}^{-1}$. It is worth noting that the average radium equivalent values are within the limit proposed by the OECD countries. Nevertheless, it is important to note that this recommended value is calculated for materials used in bulk amounts, and it is not appropriate for decorative building materials such as tiles.

Table 4. Worldwide average natural radionuclide content in soil [16].

\begin{tabular}{|l|c|c|c|c|}
\hline & $\begin{array}{c}{ }^{\mathbf{2 3 8}} \mathbf{U} \\
\left(\mathbf{B q ~ k g}^{-1}\right)\end{array}$ & $\begin{array}{c}{ }^{\mathbf{2 2 6}} \mathbf{R a} \\
\left(\mathbf{B q ~ k g}^{-1}\right)\end{array}$ & $\begin{array}{c}{ }^{\mathbf{2 3 2}} \mathbf{T h} \\
\left(\mathbf{B q ~ k g}^{-\mathbf{1}}\right)\end{array}$ & $\begin{array}{c}{ }^{\mathbf{4 0}} \mathbf{K} \\
\left(\mathbf{B q ~ k g}^{-\mathbf{1}}\right)\end{array}$ \\
\hline Mean & 35 & 35 & 30 & 400 \\
\hline Range & $16-110$ & $17-60$ & $11-64$ & $140-850$ \\
\hline Population weighted average & 33 & 32 & 45 & 420 \\
\hline
\end{tabular}

Gamma indexes summary statistics of the samples are shown in table 2 and 3. The gamma index (I) has been found to be varying from 0.48 to 0.96 in porous fired tiles and 0.34 to 3.2 in porcelain stoneware tiles. The European Commission [2] suggests that building materials should be exempted from all restrictions concerning their radioactivity if the excess gamma radiation originating from them increases the annual effective dose of a member of the public by $0.3 \mathrm{mSv}$ at the most, corresponding to a gamma index $\leq 1$ (See Table 1). On the contrary, doses higher than $1 \mathrm{mSv}$ (corresponding to a gamma index $>6$ ) should be accepted only in some very exceptional cases, when materials are used locally. 
Table 5. Comparison of activity concentrations and radium equivalent activities in ceramic tiles in different areas of the world.

\begin{tabular}{|l|c|c|c|c|l|}
\hline Country & ${ }^{\mathbf{2 2 6}} \mathbf{R a}$ & ${ }^{\mathbf{2 3 2}} \mathbf{T h}$ & ${ }^{\mathbf{4 0}} \mathbf{K}$ & $\mathbf{R a}_{\mathbf{e q}}$ & Reference \\
\hline South Korea & $44-82$ & $34-96$ & $310-1019$ & $124-264$ & Lee et al. [17] \\
\hline Algeria & 55 & 41 & 410 & 145 & Amrani \& Tahtat [14] \\
\hline India & 28 & 64 & 24 & 121 & Kumar et al. [18] \\
\hline China & $64-131$ & $55-107$ & $561-867$ & $200-331$ & Xinwei [19] \\
\hline Egypt & $40-230$ & $10-130$ & $80-600$ & & Ahmed [15] \\
\hline Egypt & $61-118$ & $55-98$ & $730-1050$ & 267 & El Afifi et al. [20] \\
\hline Greece & $25-174$ & $29-47$ & $411-786$ & & Krstić et al. [21] \\
\hline Spain & $75-191$ & $68-76$ & $507-490$ & & Serradell et al. [22] \\
\hline Italy (porous fired tiles) & $27-88$ & $42-69$ & $544-977$ & & Bruzzi et al. [23] \\
\hline Italy (porcelain stoneware tiles) & $39-247$ & $40-92$ & $528-1000$ & & Bruzzi et al. [23] \\
\hline Italy (porous fired tiles) & $36-87$ & $38-86$ & $411-996$ & $130-261$ & Present study \\
\hline Italy (porcelain stoneware tiles) & $20-708$ & $33-145$ & $158-850$ & $93-943$ & Present study \\
\hline
\end{tabular}

All porous fired tiles show gamma indices lower than 1 . Twelve porcelain stoneware tiles show gamma indices higher than 1 . None of the samples show a gamma index higher than 6 .

Activity concentrations and radium equivalent activities for porous fired and porcelain tiles are compared with results obtained by other authors in Table 5. As it is possible to observe, activity concentration maximum values of porcelain stoneware tiles result much higher than those reported by the other authors, and than those measured in porous fired tiles in this study. Despite employing different technologies, this difference between porous fired and porcelain stoneware tiles was also observed in a previous Italian study (see Table 5) [23].

\section{CONCLUSIONS}

Activity concentrations of ${ }^{226} \mathrm{Ra},{ }^{232} \mathrm{Th}$ and ${ }^{40} \mathrm{~K}$ were measured and next radium equivalent activities and gamma indexes were calculated in a number of Italian ceramic tiles. The authors divided tile samples into two group: porous fired tiles and porcelain stoneware tiles. Results confirm that mean values measured in porous fired tiles are comparable with mean worldwide value in earth crust, instead natural activity concentrations in porcelain stoneware tiles are found slightly higher than those averagely measured in soils. Probably, the higher natural activity concentrations found in porcelain stoneware tiles is due to the larger amount of zircon added with respect to porous fired tiles. From a radiological point of view, the results indicate that the use of these materials in construction of dwellings could be considered safe for inhabitants. As matter of fact, all samples show gamma indexes much lower than the limit indicated by the European Commission and, except some porcelain stoneware tiles, in all samples the radium equivalent activity is within the limit set by the OECD.

\section{Acknowledgments}

This work could not have been carried out without the collaboration with of the Health Physics Service of Ravenna Hospital and the skilful technical assistance of M. Carnevali and C. Orlandi. The authors wish to express their deep appreciation to the Institute of Advanced Studies for awarding a scholarship for Young Researchers to Dr. M. Jeyapandian to conduct a semestral activity of research at the Interdepartmental Centre for Environmental Science Research of Bologna University. The authors also are grateful to Prof. L. Bruzzi for his helpful suggestions and advice. Finally, the authors would like to thank Dr. G. Bonvicini and E. Rastelli of Ceramic Centre of Bologna for the kind assistance in supplying and preparing the samples. 


\section{References}

[1] NRPB Working with Zircon Sands, NRPB Broadsheet Series (1993).

[2] European Commission Radiation protection 112, Directorate-General Environment, Nuclear Safety and Civil Protection (1999).

[3] OECD Exposure to radiation from the natural radioactivity in building materials (1979).

[4] J. Beretka and P.J. Mathew, Health Phys. 48, 87 (1985).

[5] UNSCEAR Sources, Effects and Risks of Ionizing Radiation (1993).

[6] Materials Markets Consulting Markets for zircon, p. 41 (2002).

[7] E.M. Krisiuk, S.I. Tarasov, V.P. Shamov, N.I. Shalak, E.P. Lisachenko and L.G. Gomelsky, A study on radioactivity in building materials, Leningrad Research Institute for Radiation Hygiene (Leningrad, 1971)

[8] E. Stranden, Phys. Norv. 8, 167 (1976).

[9] R. Krieger, Betonwerk Fertigteil Tech. 47, 468 (1981).

[10] G.A. Swedjemark, Health Phys. 51, 569 (1986).

[11] L. Bruzzi, R. Mele and F. Padoani, J. Radiological Protection 12, 67 (1992).

[12] L. Bruzzi, M. Baroni, G. Mazzotti, R. Mele and S. Righi, J. Environ. Radioactiv. 47, 171 (2000).

[13] S. Righi, S. Verità, P.L. Rossi and L. Bruzzi, in Proceeding of the International Conference on Radioactivity in the Environment, Nice, 2005, edited by P. Strand, P. Borretzen, T. Jolle (NRPA, Østerås, 2005) pp. 91-94.

[14] D. Amrani, M. Tahtat, Appl. Radiat. Isotopes 54, 687 (2001).

[15] N.K. Ahmed, J. Environ. Radioactiv. 83, 91 (2005).

[16] UNSCEAR Sources and Effects of Ionizing Radiation (2000)

[17] S.C. Lee, C.K. Kim, D.M. Lee and H.D. Kang, Radiat. Prot. Dosim. 94, 269 (2001).

[18] A. Kumar, M. Kumar, B. Singh and S. Singh, Radiat. Meas. 36, 465 (2003).

[19] L. Xinwei, Radiat. Prot. Dosim. 112, 323 (2004).

[20] E.M. El Afifi, M.A. Hilal, S.M. Khalifa and H.F. Aly, Radiat. Meas. 41, 627 (2006).

[21] D. Krstić, D. Nikezić, N. Stevanović and D. Vučić, Radiat. Meas. 42, 1731 (2007).

[22] V. Serradell, J. Ortiz, L. Ballesteros and I. Zarza, in CD of the 5th International Symposium on NORM, Seville, 2007, edited by R. García-Tenorio, G. Manjón (Universidad de Sevilla, Sevilla, 2007).

[23] L. Bruzzi, S. Cazzoli, R. Mele and A. Tenaglia, Cer. Acta 3, 27 (1991). 
